\title{
Developmental and hyperthermia-induced expression of the heat shock proteins HSP60 and HSP70 in tissues of the housefly Musca domestica: An in vitro study
}

\author{
Sunita Sharma, Manoj Singh Rohilla and Pramod Kumar Tiwari \\ School of Studies in Zoology, Jiwaji University, Gwalior, India.
}

\begin{abstract}
The expression pattern of two major chaperones, the heat shock proteins (HSPs) HSP60 and HSP70 was studied in vitro in tissues of the housefly Musca domestica during larval and adult stages of development to identify their immunological relatives and understand their functional significance in normal cellular activities and during thermal stress. Fluorographs of labeled polypeptides and western blots demonstrated that both HSPs are expressed constitutively and heat-induced in all the larval and adult cell types examined. The pattern of whole tissue immunocytochemical staining using anti-HSP60 and anti-HSP70 antibodies corresponded well with the observations from western blots or fluorographs. In developing oocytes, both constitutive and heat inducible expression of HSP60 were regulated in an oocyte stage-specific manner. In unstressed ovaries the expression of these proteins was less pronounced in early stage oocytes $\left(1^{\text {st }}-8^{\text {th }}\right)$ than at later stages ( $9^{\text {th }}$ and onward). The heat shock, however, induced both HSP70 and HSP60 to a significantly high level in early stage oocytes $\left(1^{\text {st }}-8^{\text {th }}\right)$ as compared to their respective controls. Our findings indicate the involvement of the HSP60 and HSP70 proteins in the development, growth and differentiation of both somatic and germ line tissues. Furthermore, the enhanced co-expression of HSP70 and HSP60 upon heat shock in various larval and adult cell types suggests the possible role of HSP60 in thermoprotection.
\end{abstract}

Key words: heat stress response, HSP60, HSP70, Musca domestica, thermoprotection, housefly.

Received: May 22, 2006; Accepted: August 17, 2006.

\section{Introduction}

Temperature plays a key role in the survival of an organism up to a certain threshold. Almost every organism, therefore, possess a cellular mechanism to safeguard it from the injurious effect of heat stress through a unique class of proteins, the molecular chaperones or heat shock proteins (HSPs) (Feder and Hofmann 1998; Morimoto et al., 1994; Kregel 2002; Sorensen et al., 2003). These proteins, and their cognates, help in the maintenance of cellular homeostasis under both normal and stressed conditions (Feder and Hofmann 1999; Nover 2000) and also have significant adaptive functions during natural stress conditions (Currie and Tufts 1997; Singh and Lakhotia 2000; Zatsepina et al., 2000). The two most conserved HSPs, HSP60 and HSP70, are regarded as cytoprotective and essential for the development of thermotolerance (Dahlgaard et al., 1998; Bettencourt et al., 1999; Nollen et al., 1999; Brown et al., 2004; Sharma et al., 2006). Besides these functions, HSPs are also involved in protein folding, re-

Send correspondence to Pramod Kumar Tiwari. School of Studies in Zoology, Jiwaji University, Gwalior 474 011, M. P., India. E-mail: pk_tiwari@ hotmail.com. moval of misfolded aggregates, prevention of nascent protein substrates from misfolding or denaturation during stress, etc. (Hartl and Hayer-Hartl 2002; Kregel 2002; Craig et al., 2003; Soti et al., 2005).

Temperature is a major limiting factor for survival of small ectotherms, such as the flies, as they often remain exposed to extreme thermal variations in their natural habitat, particularly during summer months. Under such conditions they are expected to be highly susceptible to heat induced injuries. The synanthropic housefly Musca domestica is a potent vector of various human pathogens and passes its life cycle in highly diverse and physiologically challenging habitats. In an earlier study of $M$. domestica distinct and enhanced (Tiwari et al., 1997) expression of various heat induced polypeptides were observed in the fluorographs of radio-labeled proteins from different tissues-types, exposed to an increasing thermal gradient $\left(37^{\circ} \mathrm{C}\right.$ to $\left.48{ }^{\circ} \mathrm{C}\right)$. The patterns of expression of heat induced polypeptides at increased temperatures were correlated with the percentage survival of larval and adult flies at the corresponding temperatures. At higher or lethal temperatures $\left(46^{\circ} \mathrm{C}\right.$ to $\left.48^{\circ} \mathrm{C}\right)$ the percent survival and the level of expression of induced proteins decreased considerably. 
The study described in this paper is a sequel to our previous investigation. In the research described in the present paper we made a detailed functional characterization of two major heat induced polypeptides, HSP60 and HSP70, which are widely implicated in thermoprotection and various other cellular functions. The aims were (i) to identify the immunological relatives of the HSP60 and HSP70 proteins in $M$. domestica, (ii) study the intracellular distribution of these proteins and (iii) analyze the pattern of their expression and possible functional significance in different larval and adult tissue types, including germ-line tissues such as ovary, during the normal course of development and heat stress. The HSP70 and HSP60 proteins both were found distinctly heat inducible in all the tissue types examined. The constitutive and heat induced expression of these proteins in different somatic and germ line tissues suggest their involvement in a wide variety of functions, including egg development and thermoprotection.

\section{Material and Methods}

\section{Fly cultures}

Laboratory cultures of the housefly Musca domestica (Muscidae) were maintained at between $24^{\circ} \mathrm{C}$ and $26^{\circ} \mathrm{C}$ in an insectary at our institution. The wild-type flies from which the laboratory cultures originated had been captured in the Gwalior area around 25-30 years ago and maintained in the laboratory at Defence Research \& Development Establishment since then. Milk-soaked cotton pads were used to induce egg laying and larvae were reared on rice bran meal and adult flies were fed on sugar and water.

\section{Heat shock treatment and radiolabeling of proteins}

The salivary gland (SG), brain ganglia (BG), fat body (FB), Malpighian tubule (MT), mid gut (mg) and hindgut (HG) from late $3^{\text {rd }}$ instar wandering stage $M$. domestica larvae were excised in Robb's minimal medium (Fristrom et al., 1973). Similarly, MT, FB, mg, hindgut HG, brain (B) and ovary $(\mathrm{Ov})$ were dissected out from the adult flies. The $\mathrm{mg}$, HG and MT are parts of the gut system in both larva and adult. The salivary gland and fat body are the physiologically most active larval tissues and are involved in a number of functions essential for survival. The adult brain is a well-differentiated tissue consisting of non-dividing cells and is known to be metabolically less active than other tissues. In contrast, the larval brain ganglion is mitotically very active. Similarly, the adult ovary is a vital reproductive organ and is highly sensitive to heat and chemical treatments. Thus, all the above tissues chosen in this study are essential for the survival of the fly and can serve as target tissue types for the assessment of injury caused by external stressors, including environmental heat.

We used $15 \mathrm{M}$. domestica larvae and 15 adult flies for the heat-shock experiments and the same number for the control experiments without heat-shock. For both the lar- vae and the adults, the SG, MT, FB, mg, HG, B and Ov were excised and each tissue class was pooled.Pooled tissue samples were placed in sterile pre-heated thin-walled Eppendorf tubes or glass cavity blocks containing prewarmed Robb's medium and incubated in a water-bath at the heat shock temperature of $42{ }^{\circ} \mathrm{C}$ for one hour. The heat shock experiments were repeated at the higher heat shock temperature of $44^{\circ} \mathrm{C}$. The same procedures were used for the non-shocked controls except that the temperature was $25 \pm 1{ }^{\circ} \mathrm{C}$. To radiolabel any proteins produced, radioactive $\mathrm{S}^{35}$-methionine (specific activity: $1 \mu \mathrm{Ci} \mathrm{mM}^{-1}$; activity: $100 \mu \mathrm{Ci} \mathrm{mL}^{-1}$; BRIT, Mumbai, India) was added to the incubation medium for the last $30 \mathrm{~min}$ of incubation at the heat shock or control temperature.

\section{Electrophoreses and fluorography}

The radiolabeled tissues were dissolved in Laemmli's sample buffer (50 mM Tris pH-6.8 containing $100 \mathrm{mM}$ $\beta$-mercaptoethanol plus glycerol 10\% (v/v), SDS 2\% (w/v) and bromophenol blue $0.1 \%(\mathrm{w} / \mathrm{v})$ ) (Laemmli 1970). To facilitate better dissolution of the tissue a gentle homogenization was done with a few strokes of a sterile glass rod in a sterile Eppendorf tube on ice. The undissolved tissues were removed by pelleting by centrifugation at 10,000 revs $\mathrm{min}^{-1}$ at $4{ }^{\circ} \mathrm{C}$ and the clear supernatant transferred to a fresh sterile tube. The concentration of protein in the supernatant was estimated using modified Bradford's method (Bradford, 1976) and the supernatant spotted onto one-dimensional sodium dodecyl sulfate (SDS) - $12.5 \%(\mathrm{w} / \mathrm{v})$ polyacrylamide gel. An equal quantity $(50 \mu \mathrm{g})$ of total protein, inclusive of labeled and unlabelled both, was run in each lane to separate the various polypeptides present. The SDS polyacrylamide gel electrophoresis (SDS-PAGE) was run at $120 / 150 \mathrm{~V}$ (for stacking/separation) for $5 \mathrm{~h}$ and the amount of proteins in each lane monitored by Coomassie brilliant blue (CBB) staining. The gel was destained and dehydrated in 20 volumes of dimethyl sulfoxide (DMSO), impregnated with 2,5-diphenyloxazole (PPO), vacuum dried and exposed to X-ray film for autoradiography as described in Tiwari et al. (1995).

\section{Western blotting (immunodetection) of HSP60 and HSP70 polypeptides}

Western blotting was adapted from Sambrook et al., (1989). Equal quantities of heat stressed and control tissue protein samples $(50-80 \mu \mathrm{g})$ were loaded onto separate SDS-PAGE lanes and electrophoresed and the polypeptides were electroblotted from the PAGE onto Hybond nitrocellulose membranes (Amersham Biosciences, Hong Kong). The efficiency of transfer and equality of proteins in each lane was carefully monitored by Ponceau-S (Sigma, USA) staining. The transferred proteins were blocked with $5 \%(\mathrm{w} / \mathrm{v})$ fat-free milk (Himedia, India) and then washed in PBT (phosphate buffered saline (PBS) containing 0.1\% 
(v/v) Tween-20 (Sigma, USA) for $30 \mathrm{~min}$. The blots were incubated in 1:1000 Heliothis anti-HSP60 polyclonal antibody or mouse anti-HSP70/HSC70 monoclonal antibody (Cat. Nos. SPA-805 and SPA-822, respectively; StressGen Biotech, Canada) for one hour and then washed for $30 \mathrm{~min}-$ utes in PBS containing $0.1 \%$ Tween-20. The blots were further incubated in anti-rabbit-IgG-HRP conjugate for anti-HSP60 antibody or anti-mouse-IgG-HRP conjugate for anti-HSP70/HSC70 antibody (Amersham Biosciences, Hong Kong) followed by one 15 min wash in PBT (PBS containing $0.2 \%(\mathrm{v} / \mathrm{v})$ Tween-20) and another in PBS containing $0.3 \%(\mathrm{v} / \mathrm{v})$ Tween-20. The cross-reacting protein band signals (Western signals, i.e. bands) were detected using the ECL-Plus detection system (Amersham Biosciences, Hong Kong). The intensities of the western signals were measured in arbitrary optical density (OD) units using the UVItech gel doc system (UVItech, U. K.) and the UVIband software program, taking the first blank lane as a reference. Densitometric analysis was only carried out on those blots which showed optimal band intensity in each lane or the best resolution for each band. The densitometric measurement (as arbitrary OD units) taken by the software were automatically plotted as histograms.

\section{Immunostaining of HSP60 and HSP70}

Immunostaining was adapted from Ashburner (1989). The heat shocked and control tissues were fixed in $4 \%(w / v)$ paraformaldehyde (Sigma, USA) and the endogenous peroxidase activity quenched with $0.3 \%(\mathrm{v} / \mathrm{v})$ hydrogen peroxide (Merck, India). After subsequent washing in PBS supplemented with $0.1 \%$ bovine serum albumin (BSA) and $0.1 \%$ Triton X-100 (Himedia, India) the tissues were blocked in blocking buffer containing 3\% BSA. The tissues were washed again with wash buffer (PBS with $0.3 \%$ BSA and $0.1 \%$ Triton X-100) and then incubated overnight at $4{ }^{\circ} \mathrm{C}$ with 1:200 dilutions of Heliothis antiHSP60 polyclonal antibody or mouse anti-HSP70/HSC70 monoclonal antibody and washed again in the same buffer mixture before incubation with the secondary antibodies, 1:200 dilutions of anti-rabbit IgG-HRP conjugate for HSP60 or anti mouse-IgG-HRP conjugate (Amersham Biosciences, Hong Kong) for anti-HSP70/HSC70. Protein localization was made by chromogenic staining using 3,3'-diaminobenzidine tetrahydrochloride (DAB; Sigma, USA). Stained tissues were mounted in $50 \%(\mathrm{v} / \mathrm{v})$ glycerol and photographed under a Nikon (Japan) photomicroscope. As with somatic tissues, different stages of oocytes were also immunostained, using the method described above, to detect the cellular distribution of HSP60 protein in developing oocytes or egg chambers.

All the autoradiography, western blotting and immunostaining experiments were repeated 2-3 times or more for reproducibility of the results.

\section{Results}

\section{Expression pattern and immuno-identification of HSP60 and HSP70-related proteins}

The fluorographs of larval tissues showed induction of three major proteins with approximate molecular weights of $72 \mathrm{kDa}, 62 \mathrm{kDa}$ and $54 \mathrm{kDa}$ at heat shock temperatures of $42{ }^{\circ} \mathrm{C}$ and $44{ }^{\circ} \mathrm{C}$ as compared to their levels in $25^{\circ} \mathrm{C}$ controls, where they were poorly expressed (Figure $1 \mathrm{~A})$. The $54 \mathrm{kDa}$ protein was significantly high in all the tissues. The western blot analysis of larval and adult tissues distinctly identified the $62 \mathrm{kDa}$ protein as a HSP60 homologue and the $72 \mathrm{kDa}$ protein as a HSP70 homologue as single bands for each antigen (Figures $1 \mathrm{~B} \& \mathrm{C}$ and $2 \mathrm{~B} \& \mathrm{C}$ ).

In larval tissues, the expression of the HSP60 was observed to be both constitutive as well as heat inducible (Figure 1B). However, the level of heat stress induction of HSP60 relative to controls appeared to vary in different tissues, being higher in salivary gland, fat body, hindgut and brain ganglia than in Malpighian tubules or midgut tissue. Western blotting for HSP70 showed a similar heat induced expression pattern in that the response was tissue-specific. The level of this heat shock protein was higher in brain and hindgut than in the other tissues (Figure 1C).

Similar to the situation in larval tissues, autoradiographs of adult tissues showed both constitutive and heatinduced tissue specific expression of the HSP60 (62 kDa) protein. The HSP70 (72 $\mathrm{kDa}$ ) protein was expressed much less than the HSP60 protein and was only weakly heat induced as compared to its constitutive expression in control tissues (Figure 2A). There was no significant difference between the expression pattern of these proteins in adult tissues, heat shocked at $44{ }^{\circ} \mathrm{C}$ or $42{ }^{\circ} \mathrm{C}$, so we have only presented the results of the $42{ }^{\circ} \mathrm{C}$ treatment. The western blots of adult tissues also showed significant constitutive and heat induced expression of HSP60, which was higher in Malpighian tubules than in the other tissues (Figure 2B), while heat induction of HSP70 was higher in Malpighian tubule and hind gut tissues than in the other tissues (Figure 2C).

The expression pattern of both the HSP60 and HSP70 related proteins during oocyte development was of particular interest. Both proteins were found to be heat induced at all stages of oogenesis but in a stage-specific manner. While the constitutive expression of the HSP60 protein in the fluorographs of early (up to the $8^{\text {th }}$ stage) oocytes was very low, significantly high expression was detected at later stages $\left(9^{\text {th }}\right.$ to $\left.14^{\text {th }}\right)$. In contrast, heat shock treatment altered the induction pattern of the HSP60 protein (Figure 3A) so that it was highest in early stage oocytes (up to the $8^{\text {th }}$ stage) as compared to later stage oocytes. Likewise, high level expression of the HSP70 protein was detected at all the oocyte stages upon heat shock, however, as in the case of the HSP60 protein, weak constitutive expression of the HSP70 protein was observed in early stage $\left(1^{\text {st }}\right.$ to $\left.8^{\text {th }}\right)$ oocytes but 


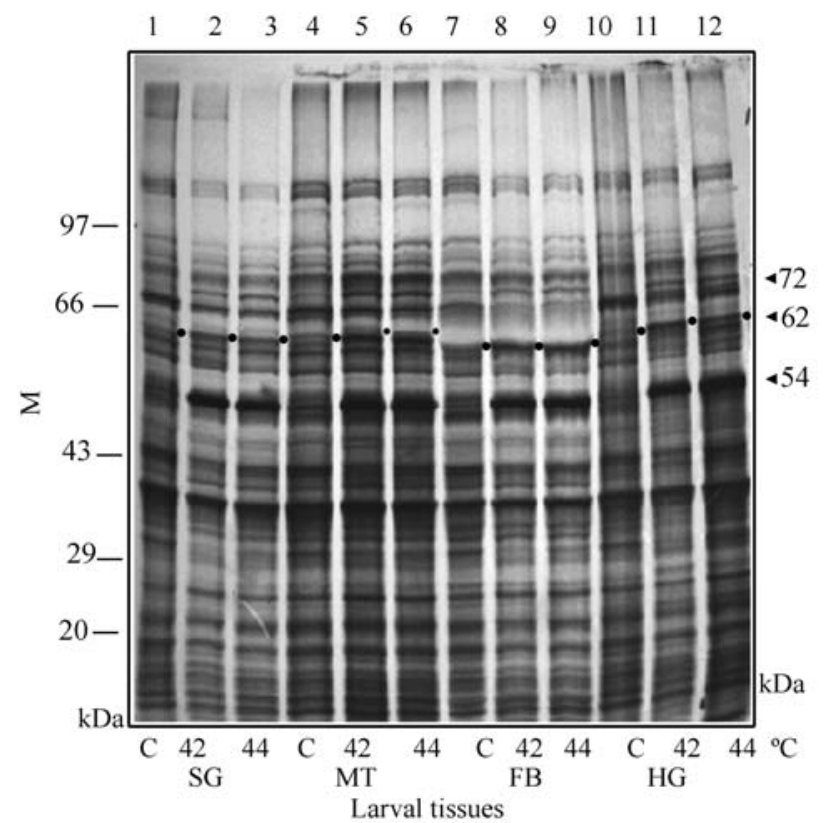

Figure 1A - Autoradiograph showing the expression patterns of the $62 \mathrm{kDa}$ (HSP60) and $72 \mathrm{kDa}$ (HSP70) proteins in $25^{\circ} \mathrm{C}$ control (C) and $42{ }^{\circ} \mathrm{C}$ and $44{ }^{\circ} \mathrm{C}$ heat shocked salivary gland (SG), Malpighian tubule (MT), fat body (FB) and hindgut (HG) tissues of larval M. domestica $(\mathrm{N}=15)$.

was significantly increased during later $\left(9^{\text {th }}\right.$ to $\left.14^{\text {th }}\right)$ stages. Thus, expression of both HSP62 and HSP72 proteins were found to be heat induced to a greater extent in early stage oocytes than in late stage oocytes, while the reverse was true for their constitutive expression (Figure 3A). In the western blots, however, the expression pattern did not show such a pronounced variation as observed in the fluorographs (Figures 3B \& C).

\section{Spatial distribution of HSP60 and HSP70 in larval and adult tissues}

Larval tissues such as salivary gland, Malpighian tubule and fat body were immunostained for in situ immunolocalization of the HSP60 protein. The immunostaining pattern of salivary gland and Malpighian tubule appeared general and uniformly weak with a slight increase in the intensity upon heat shock (not shown). The larval fat body also showed constitutive expression of the HSP60-related protein all through the tissue, which appeared somewhat induced upon heat shock (Figures 4A a, b'). The pattern of HSP70 protein in control and heat shocked tissues were the same but, compared to control tissues, heat shocked tissues showed significant expression of HSP70 as revealed by the enhancement in staining intensity (Figure 4A c-d).

The pattern of immunostaining in adult Malpighian tubule with anti-HSP60 antibody was similar to that in larva in that, as compared to control tissues, there was a slight enhancement in the intensity of immunostaining upon heat shock in adult brain tissue (not shown). Simi-
B

HSP60

(i)

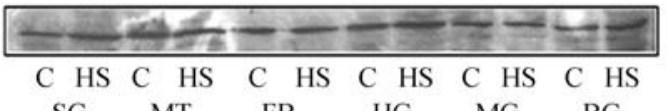

SG MT FB HG MG BG

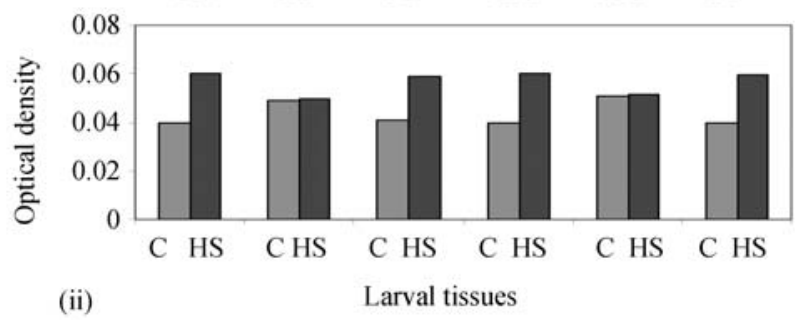

C
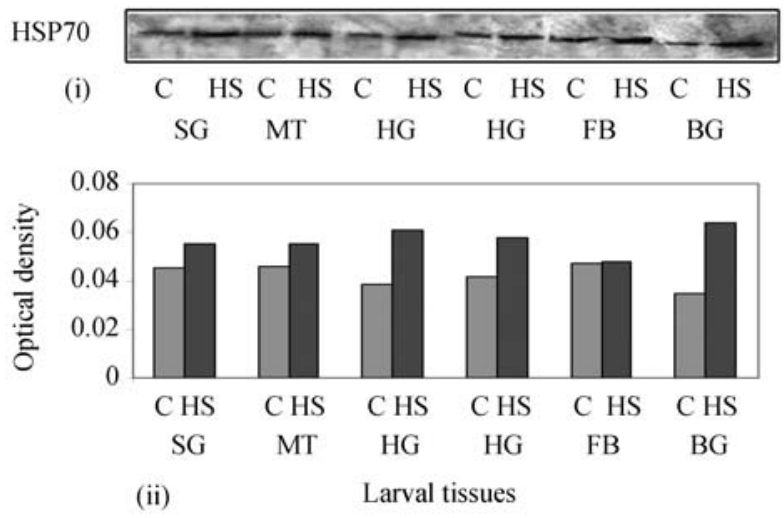

Figure 1B - (i). Western blot showing HSP60 expression in salivary gland (SG), Malpighian tubule (MT), fat body (FB), hindgut (HG), midgut $(\mathrm{mg})$ and brain ganglia $(\mathrm{BG})$ tissues of larval $M$. domestica $(\mathrm{N}=15)$ at the control $\left(\mathrm{C}, 25^{\circ} \mathrm{C}\right)$ and heat shock temperature $\left(\mathrm{HS}, 42^{\circ} \mathrm{C}\right)$. (ii) Histogram showing densitometric optical density (OD) measurement of band intensity for the corresponding western blot lanes shown in (i) above.

Figure 1C -(i). Western blot showing HSP70 expression in salivary gland (SG), Malpighian tubule (MT), hindgut (HG), midgut (mg), fat body (FB) and brain ganglia $(\mathrm{BG})$ tissues of larval M. domestica $(\mathrm{N}=15)$ at control $\left(\mathrm{C}, 25^{\circ} \mathrm{C}\right)$ and heat shock temperature ( $\left.\mathrm{HS}, 42^{\circ} \mathrm{C}\right)$. (ii) Histogram showing densitometric optical density (OD) measurement of band intensity in the corresponding western blot lanes shown in (i) above.

larly, both control and heat shocked adult fat body tissues were immunostained with a slight increase in the staining intensity of heat shocked tissues. Interestingly, the oenocytes dispersed in the fat body, appeared much more darkly-stained in heat shocked tissue than in control tissues (Figure 4A e-f'). Among the adult tissues stained with the anti-HSP70 antibody, Malpighian tubules appeared immunostained more intensely than others. The distribution of protein was uniform in most of the heat-shocked tissues. The pattern of immunostaining of fat body tissue with the HSP70 antibody was similar to that for the HSP60 protein and the immunostaining of the oenocytes was also much more intense than that of the fat cells (Figure 4A g-h'). Thus, in all the tissues examined the level of HSP70 expression or the intensity of immunostaining increased upon heat-shock as compared to controls which had not been heat shocked. 


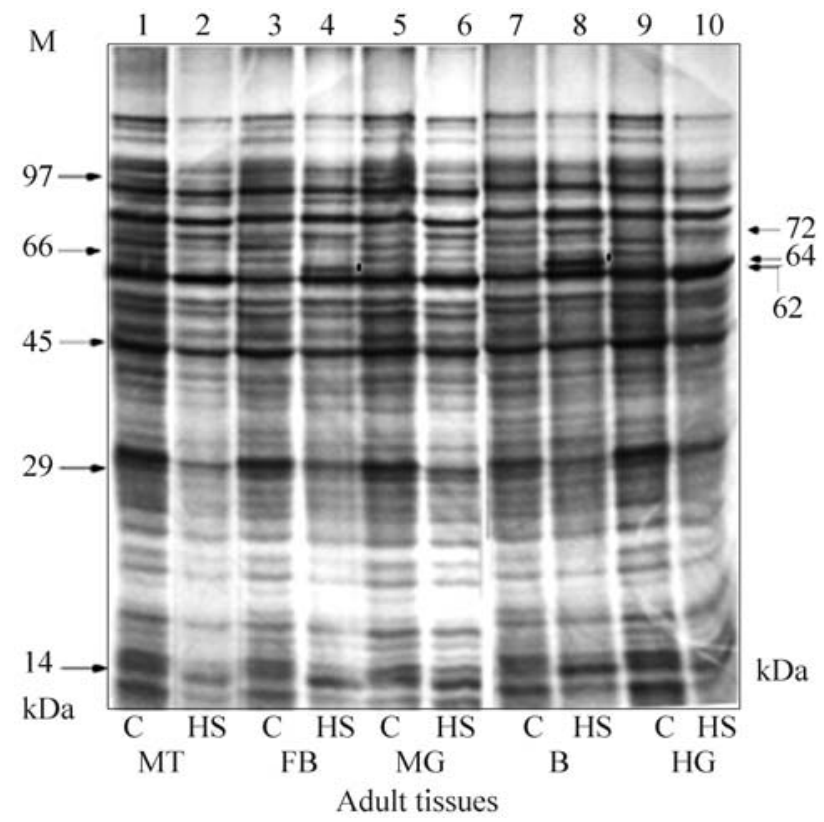

Figure 2A - Autoradiograph showing the expression patterns of the $62 \mathrm{kDa}(\mathrm{HSP} 60)$ and $72 \mathrm{kDa}(\mathrm{HSP} 70)$ proteins in control $\left(\mathrm{C}, 25^{\circ} \mathrm{C}\right)$ and heat shocked (HS, $42^{\circ} \mathrm{C}$ ) Malpighian tubule (MT), fat body (FB), midgut $(\mathrm{mg})$, brain $(\mathrm{BG})$ and hindgut $(\mathrm{HG})$ tissues of adult $M$. domestica $(\mathrm{N}=15)$. Dots in lanes 4 and 8 denote the $64 \mathrm{kDa}$ band. Histogram showing densitometric optical density (OD) measurement of band intensity in the corresponding western blot lanes shown in (i) above.

Since the general immunostaining pattern for both HSP60 and HSP70 in most of the larval and adult tissues studied appeared similar, examples of only fat body tissues are presented in the figures as representative of both developmental stages (larva and adult) to demonstrate the induced expression of both the HSP60 and HSP70 proteins, especially in oenocytes.

As with somatic tissues, different stages of oocytes were also immunostained to detect the cellular distribution of HSP60 protein in developing oocytes or egg chambers. Compared to controls, heat shocked oocytes from all the stages showed increased immunostaining, indicating distinct heat induced expression of the protein (Figure 4B a, b, $c, d, e, f$ and g). In early stage oocytes $\left(5^{\text {th }}-8^{\text {th }}\right)$ antibody staining appeared mostly localized in the posterior half (oocyte area) while the anterior nurse cell region was either unstained or poorly stained. The inner follicular cell mass surrounding the oocyte proper also appeared distinctly stained. From the $9^{\text {th }}$ stage onwards staining was prominent in the nurse cell chamber (Figure 4B c, c', d, d', e, e', f and $\left.f^{\prime}\right)$, while for the $13^{\text {th }}$ and $14^{\text {th }}$ stages the whole of the egg chambers showed a uniform distribution of the HSP60 protein (Figure 4B $g$ and $g^{\prime}$ ).

\section{Discussion}

The significant constitutive expression of both the HSP60 and HSP70 proteins in various cell types of larval and adult $M$. domestica houseflies strengthens the view that
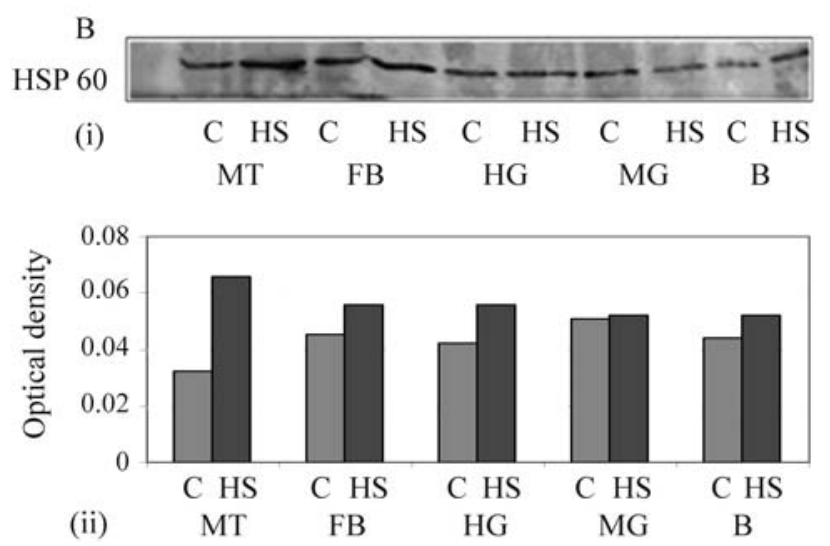

Adult tissues

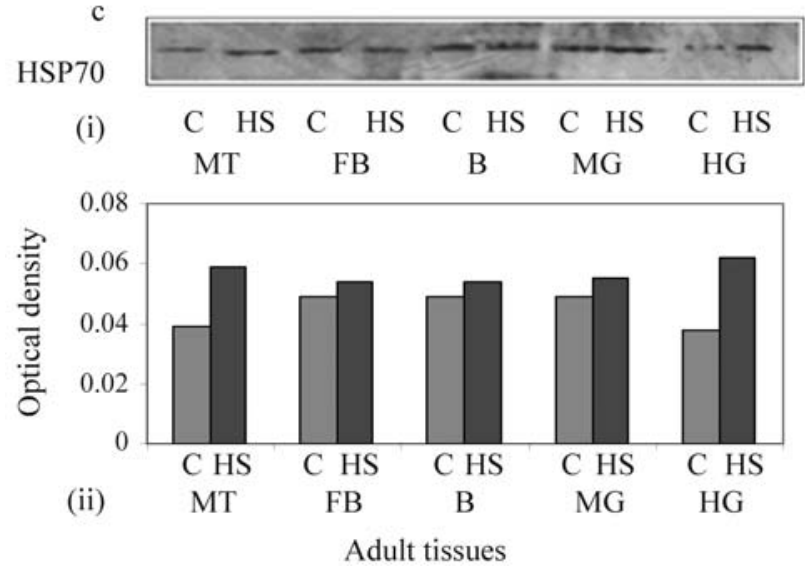

Figure 2B - (i). Western blot showing the HSP60 expression pattern in Malpighian tubule (MT), fat body (FB), hindgut (HF), midgut (mg) and brain (B) somatic tissues of adult $M$. domestica $(\mathrm{N}=15)$ at control $(\mathrm{C}$, $25^{\circ} \mathrm{C}$ ) and heat shock temperature (HS, $42{ }^{\circ} \mathrm{C}$ ). (ii) Histogram showing densitometric optical density (OD) measurement of band intensity in the corresponding western blot lanes shown in (i) above.

Figure 2C - (i). Western blot showing the HSP70 expression pattern in Malpighian tubule (MT), fat body (FB), brain (B), midgut (mg) and hindgut $(\mathrm{HG})$ tissues of adult $M$. domestica $(\mathrm{N}=15)$ at control $\left(\mathrm{C}, 25^{\circ} \mathrm{C}\right)$ and heat shock temperature (HS, $42^{\circ} \mathrm{C}$ ). (ii) Histogram showing densitometric optical density (OD) measurement of band intensity in the corresponding western blot lanes shown in (i) above.

these proteins participate in cellular homeostasis involving the natural microstressors that surround small ectotherms. However, the expressions of these proteins are regulated in manner specific to each tissue and/or development stage. Both proteins showed distinct and significant heat induction in different larval and adult tissues, with their levels being independent of each other and tissue-specific. Enhanced expression of HSP70 upon heat stress protects cells from thermally induced injuries. In contrast, only limited experimental evidence is available to conclude the same for HSP60 (Gianguzza et al., 2000; Singh and Lakhotia 2000; Sharma et al.2006). Thus, our observations on the induction of HSP60 following heat stress seems to validate further the proposed thermoprotective functions of HSP60. Malpighian tubules of D. melanogaster do not express typical HSPs such as HSP70 (Lakhotia and Singh 


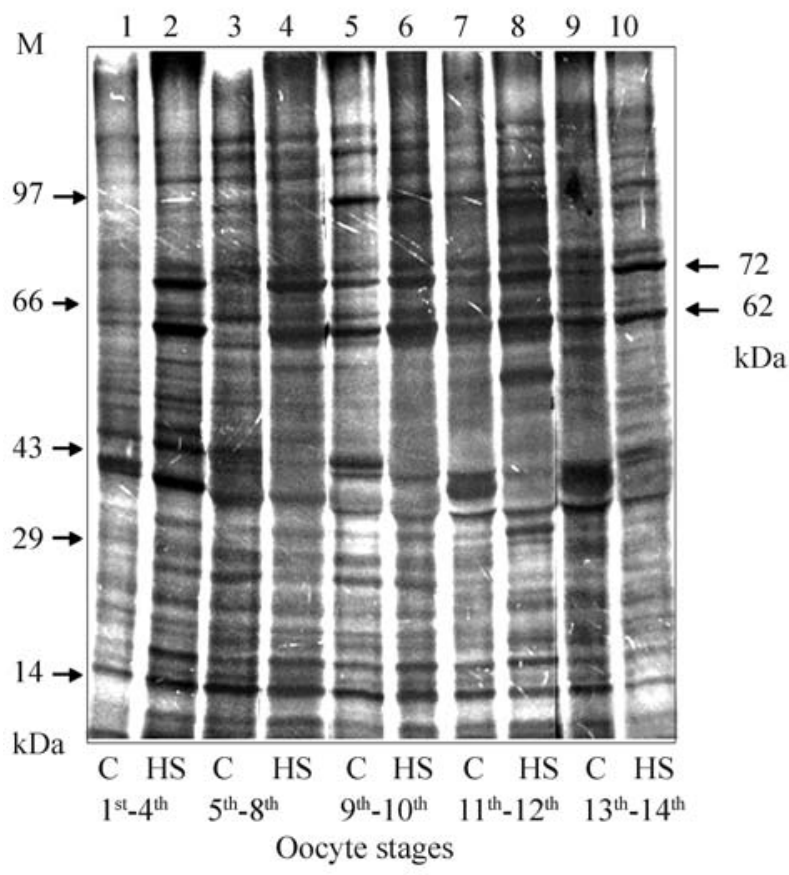

Figure 3A - Autoradiograph showing the expression patterns of the 62 $\mathrm{kDa}$ (HSP60) and $72 \mathrm{kDa}$ (HSP70) proteins during the $1^{\text {st }}-4^{\text {th }}, 5^{\text {th }}-8^{\text {th }}$, $9^{\text {th }}-10^{\text {th }}, 11^{\text {th }}-12^{\text {th }}$ and $13^{\text {th }}-14^{\text {th }}$ stages of oocyte development in $M$. domestica at the control $\left(\mathrm{C}, 25^{\circ} \mathrm{C}\right)$ and heat shocked $\left(\mathrm{HS}, 42^{\circ} \mathrm{C}\right)$ temperatures.

1996; Krebs and Feder 1997; Lakhotia et al., 2002) but, interestingly, we found that in M. domestica larval Malpighian tubules expressed most of the typical HSPs, including HSP60 and HSP70. This indicates speciesspecific regulation of expression of heat shock genes and it should be noted that both flies are close relatives which belong to the order Diptera. The enhanced heat induced synthesis of a developmental stage-specific $54 \mathrm{kDa}$ protein, significantly higher than $62 \mathrm{kDa}$ (HSP60) or $72 \mathrm{kDa}$ (HSP70) proteins, in the autoradiographs of larval tissues was striking. The apparent absence of the $54 \mathrm{kDa}$ protein in adult tissues makes it more interesting suggesting a significant role including thermoprotection in heat stressed larval tissues. Its exact nature or relationship with the other heat shock proteins is as yet undetermined.

The fat body of adult houseflies is organized as a loose network of fat cells which provide reserve materials for egg development. Oenocytes are scattered throughout and completely buried in the fat tissue. The immunostaining of fat body with HSP60 or HSP70 antibody revealed uniform cytoplasmic staining, with oenocytes staining darker than the surrounding fat cells. The oenocytes appear to bear some special relation to growth and perhaps reproduction and possibly secrete enzymes which enhance cytolysis or dissolve substances stored in the fat cells (Wigglesworth 1965). The significant amount of the HSP60 or HSP70 protein expressed in the oenocytes may play a significant role in protein folding, transport and se-
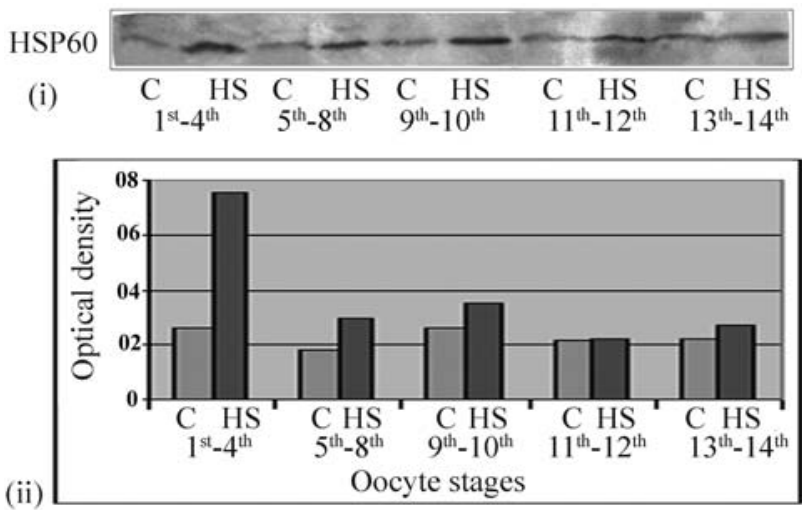

Figure 3B - (i). Western blot showing the HSP60 expression pattern during the $1^{\text {st }}-4^{\text {th }}, 5^{\text {th }}-8^{\text {th }}, 9^{\text {th }}-10^{\text {th }}, 11$ th- $12^{\text {th }}$ and 13 th- 14 th stages of oocyte development in $M$. domestica at the control $\left(\mathrm{C}, 25^{\circ} \mathrm{C}\right)$ and heat shock (HS, $42{ }^{\circ} \mathrm{C}$ ) temperatures.(ii) Histogram showing densitometric optical density (OD) measurement of band intensity in the corresponding western blot lanes shown in (i) above.

HSP70

(i)

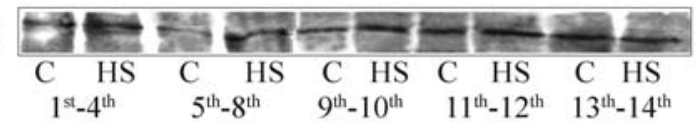

(ii)

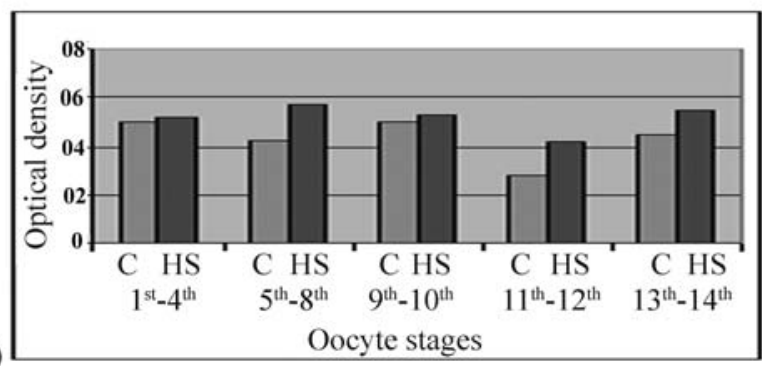

Figure 3C - (i). Western blot showing HSP70 expression pattern during the $1^{\text {st }}-4$ th $, 5^{\text {th }}-8^{\text {th }}, 9^{\text {th }}-10^{\text {th }}, 11^{\text {th }}-12^{\text {th }}$ and $13^{\text {th }}-14^{\text {th }}$ stages of oocyte development in $M$. domestica at the control $\left(\mathrm{C}, 25^{\circ} \mathrm{C}\right)$ and heat shock (HS, $42^{\circ} \mathrm{C}$ ) temperatures.(ii) Histogram showing densitometric optical density (OD) measurement of band intensity in the corresponding western blot lanes shown in (i) above.

cretion, preventing protein misfolding or the removal of denatured substrates during heat shock, etc. in both fat cells and oenocytes, as widely reported in various studies (Currie and Tufts 1997; Sejerkilde et al., 2003).

In adult flies, the ovary and testis continue their functions related to the growth and development of germ cells, egg and sperm. The growing dipteran egg contains two distinct regions, an anterior vegetative nurse cell chamber and the posterior oocyte chamber, separated by a layer of specialized follicle cells including border cells (King 1970; Spradling 1993). The role of HSPs during the process of germ cell differentiation has been suggested to be significant, although their full functions are still unclear.

We found that in M. domestica both the HSP60 and HSP70 proteins were expressed in the $25{ }^{\circ} \mathrm{C}$ control oocytes and that there was a significant increase in their 


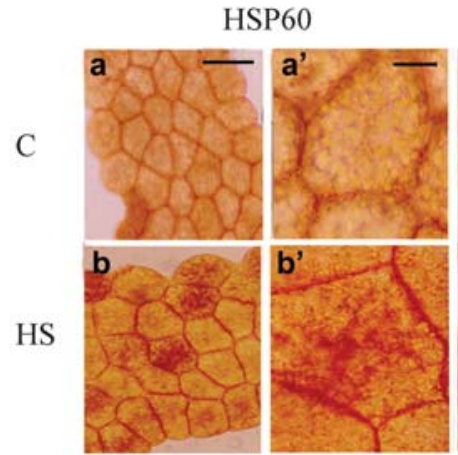

Larval tissues
HSP70
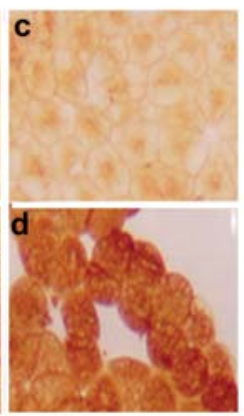
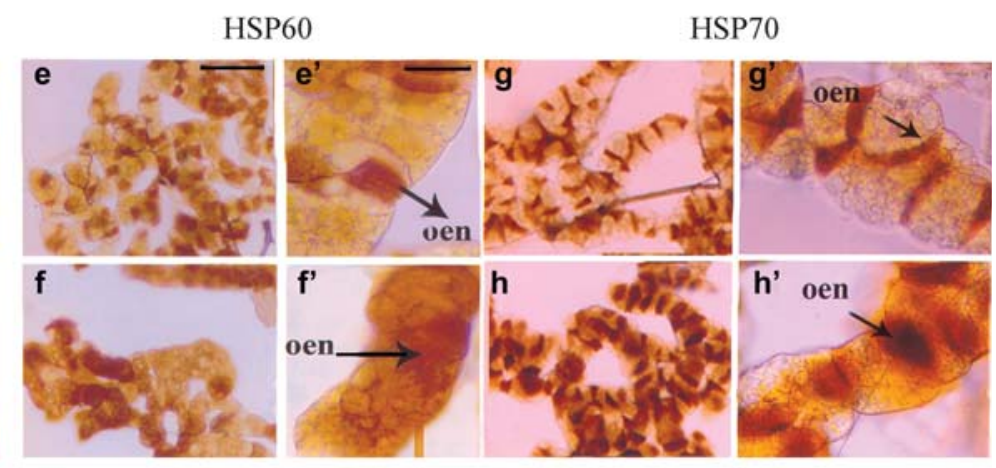

Adult tissues

Figure 4A - Immunocytochemical staining of larval (FB, a-d) and adult (FB, e-h') fat body tissues of M. domestica showing in situ expression of HSP60 (a, a', b, b', e, e', f \& f') and HSP70 (c, d, g, g', h \& h') proteins. Figures a, a', e, e', c, g and g' represent the control (C, $\left.25^{\circ}{ }^{\circ}\right)$ and b, b', d, f, f', h and h' the heat shocked (HS, $42^{\circ} \mathrm{C}$ ) tissues. Bar represents $100 \mu \mathrm{m}$ in figures a, b, c, d, e, f, g and h and $20 \mu \mathrm{m}$ in figures a', b', e', f', g' and h'. Oenocytes = oen.

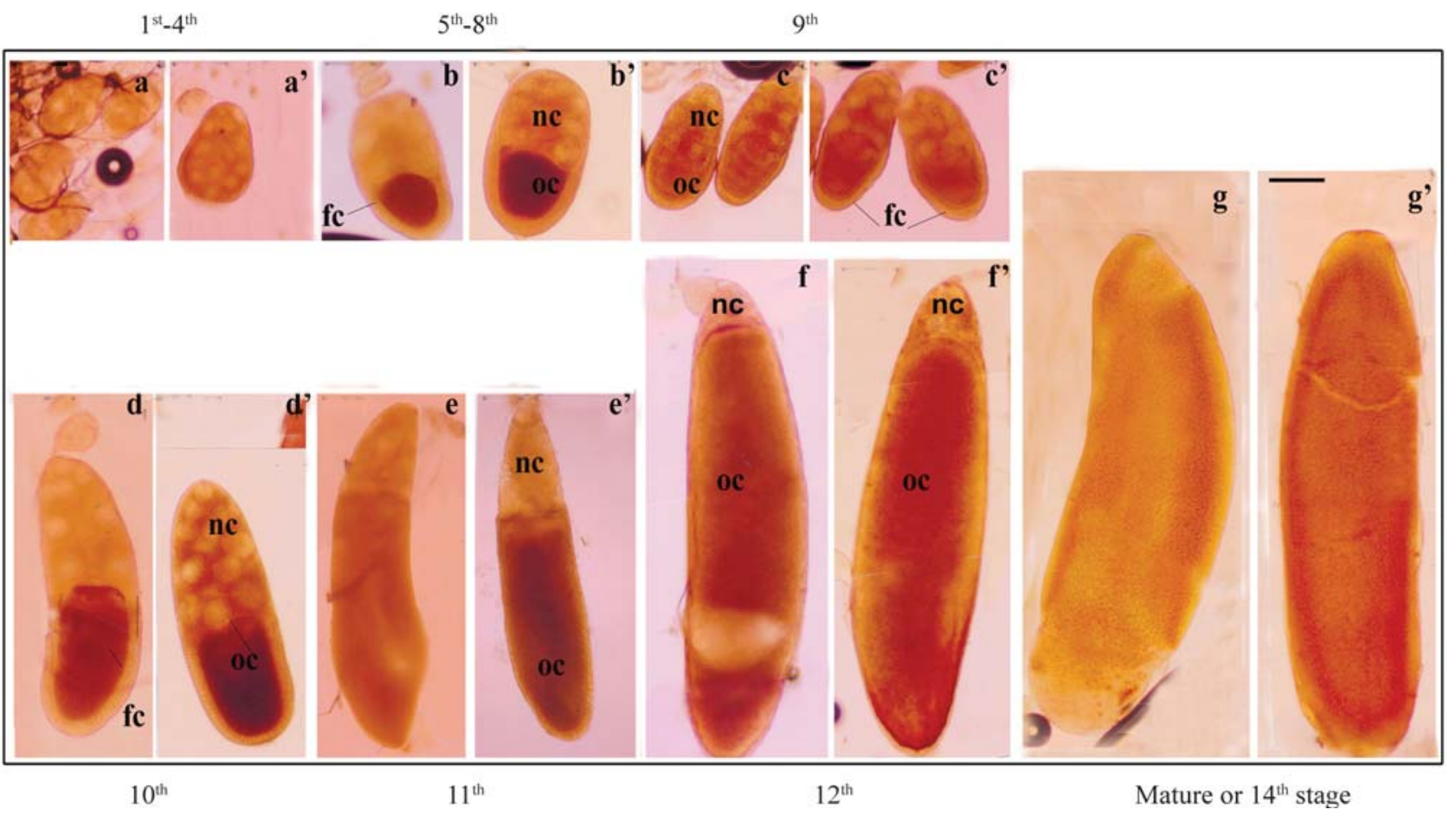

Figure 4B - Immunocytochemical staining of adult ovary to demonstrate in situ expression of HSP60 during the $1^{\text {st }}-4^{\text {th }}$ (a, a'), 5th- 8th (b, b'), 9th (c, c'), 10th (d, d'), 11th (e, e'), 12th (f, f') and 14th ( $g$, g') stages of oocyte development in M. domestica. Figures a, b, c, d, e f and g represent controls (C, $\left.25^{\circ} \mathrm{C}\right)$ and a', b', c', d', e' f' and g' representing heat shocked (HS) oocytes. Bar represents $100 \mu \mathrm{m}$ in each figure. Oocyte $=$ oc; nurse cells $=$ nc; and follicle cells $=$ fc.

levels upon heat shock at $42^{\circ} \mathrm{C}$ and $44^{\circ} \mathrm{C}$, with the expression pattern of these proteins being specific to the oocyte stage. For the non-shocked controls the fluorographs of labeled proteins showed no marked expression of either the $62 \mathrm{kDa}$ (HSP60) or $72 \mathrm{kDa}$ (HSP70) proteins during the early stages of oocyte growth (up to the $8^{\text {th }}$ stage) compared to their levels at later stages $\left(9^{\text {th }}-14^{\text {th }}\right)$, which were very high. In contrast, heat shock caused much higher expression of these proteins in early stage $\left(1^{\text {st }}-8^{\text {th }}\right)$ oocytes than in later stage $\left(9^{\text {th }}-14^{\text {th }}\right)$ oocytes. The poor constitutive expres- sion of HSP60 or HSP70 during early stages could be due to a low rate of transcription or limited cellular requirement compared with the later stages when rapid growth and gene activity occurs. The significant increase in the heat-induced synthesis of these proteins during the early $\left(1^{\text {st }}-8^{\text {th }}\right)$ stages can be accounted for by the level of thermal stress inflicted on them or their increased response (susceptibility) to temperature shock. The relatively lower level of heat induced expression of these proteins during the later oocyte stages $\left(9^{\text {th }}-14^{\text {th }}\right)$ may have been due to pre-existing (constitutive) 
HSP60or HSP70 proteins or a thermoprotective mechanism against heat stress in the growing oocytes as evidenced by the western blots. In adult female Drosophila virilis, heat shock was reported to cause multiple dysfunctions during oogenesis, such as delayed maturation of oocytes, degradation of the early vitellogenic egg chamber and inhibition of expression of several maternal genes in ovarian follicle cells (Gruntenko et al., 2003). Our observation in the common housefly is, therefore, highly significant. The presence of prominent signals in western blots of the control samples from early stage oocytes, as compared to fluorographs, were to be expected because the antibody detects both preexisting and newly synthesized proteins while fluorographs detect only newly synthesized proteins.

The expression of HSPs has been reported to be an integral part of the process of egg development in insects (Zimmermann et al., 1983; Ambrosio and Schedl 1984; Lakhotia and Singh 1996; Sharma et al.2006), fish and amphibia (Heikkila et al., 1985, 1997) and mammals (Heikkila et al., 1986; Dix and Luft 1999), suggesting their essential role in the development and differentiation of germ cells. Our observation on the expression of HSP60 and HSP70 and the spatial distribution of HSP60 antibody in the developing oocytes of $M$. domestica, appear in good agreement with the observations mentioned above in other insects and mammals. The poor staining of nurse cells with HSP60 antibody in some of our preparations may have been due to weak or low penetrance of the antibody into the egg chamber, particularly the nurse cell chamber. Our housefly results appear to be generally comparable to those reported for mice or rat oocytes for which the heat shock response has also been found to be regulated in an oocyte developmental stage specific manner, the response being highest during the growth period, declining significantly with the acquisition of maturity and is fully shut off with oocyte follicle terminal differentiation (Curci et al., 1991; Paranko et al., 1996). In the post-natal rat ovary HSP60 is expressed at folliculogenesis, suggesting it to be a key element for the proper folding of imported mitochondrial proteins (Paranko et al., 1996). Whether or not the presence of a high titer of the steroid hormone $\beta$-ecdysone in the developing oocytes of insects is a likely inducer of HSP60 or HSP70 during oogenesis, need some consideration here. In Drosophila, increased ecdysterone levels during the late third instar larval or early pupal stages has been found to correspond with the increased expression of certain low molecular weight heat shock proteins, such as HSP23 and HSP27 (Sirotkin and Davidson 1982; Ireland and Berger 1982). No other HSPs, including HSP70 or HSP60 were reported to be induced by ecdysterone during these stages. During egg development the ovarian titer of ecdysterone has been reported to be high during the early stages of oocyte development, being replaced by juvenile hormone (JH) at later stages (Soller et al., 1999; Kozhanova 2000; Rauschenbach et al., 2003). During oogenesis HSP27 has been found to be expressed throughout oocyte development (Michaud et al., 1997). In one of the earlier studies also, significant accumulation of $h s p 83, h s p 28$ and $h s p 26$ mRNAs was observed in the ovaries of adults and early embryos of $D$. melanogaster but no other hsp gene transcript was observed before heat shock (Zimmerman et al., 1983). Although in our present study no specific queries were asked on the role of these hormones (ecdysterone and or $\mathrm{JH}$ ) in the induction of HSP70 or HSP60 or both, it still remains an open question to be investigated further. Thus, the significant constitutive expression of HSP60 and/or HSP70 observed in the growing oocytes of $M$. domestica indicates the independent regulation of these heat shock proteins and their involvement in some essential function in oocyte development and maturation. The increased synthesis of these proteins upon heat shock also implies a role in thermoprotection. These observations are interesting and need to be pursued further. Though the evidence is preliminary, we presume that the distinct and significant presence or expression of the HSP 60 protein in the developing ovarian follicles of $M$. domestica might have some important association with certain essential functions such as protein targeting, transport and chaperoning of the nascent proteins being transported from nurse cells to oocyte, etc.

The results of the our study with $M$. domestica thus provides strong support to the earlier proposition from our group and elsewhere regarding the possible thermoprotective role of HSP60, similar to that widely suggested for HSP70. The observed HSP60 expression pattern in germ line tissues such as ovary indicates that HSP60 provides an important contribution to the development and maturation of eggs. Our ongoing studies are expected to provide clues on these and other unresolved issues.

\section{Acknowledgments}

The financial support to carry out this work was provided by the Department of Atomic Energy (DAE), Government of India, through a research grant to PKT. The senior research fellowship (SRF) provided by Council of Scientific \& Industrial Research (CSIR), Government of India, to SS is gratefully acknowledged. We are thankful to PVJ Reddy for providing technical help and Professor B. G. Kapoor for critically reviewing the manuscript.

\section{References}

Ambrosio L and Schedl P (1984) Gene expression during Drosophila melanogaster oogenesis: Analysis by in situ hybridization to tissue sections. Dev Biol 105:80-92.

Ashburner M (1989) Drosophila: A Laboratory Handbook and Manual. Cold Spring Harbor Laboratory Press, New York, pp 214-219.

Bettencourt BR, Feder ME and Cavicchi S (1999) Experimental evolution of HSP70 expression and thermotolerance in Drosophila melanogaster. Evolution 53:484-492. 
Bradford MM (1976) Rapid and sensitive method for the quantitation of microgram quantities of protein utilizing the principle of protein dye-binding. Anal Biochem 72:248-254.

Brown HM, Briden A, Stokell T, Griffin FJ and Cherr GN (2004) Thermotolerance and Hsp 70 profiles in adult and embryonic California native oysters, Ostreola onchaphila (Carpenter, 1857). J Shellfish Res 23:135-141.

Curci A, Bevilacqua A, Fiorenza MT and Mangia F (1991) Developmental regulation of heat shock response in mouse oogenesis: Identification of differentially responsive oocyte classes during Graffian follicle development. Dev Biol 144:362-368.

Currie S and Tufts B (1997) Synthesis of stress protein 70 (Hsp70) in rainbow trout (Oncorhynchus mykiss) red blood cells. J Exp Biol 200:607-614.

Dahlgaard J, Loeschcke V, Michalak P and Justesen J (1998) Induced thermotolerance and associated expression of the heat-shock protein Hsp70 in adult Drosophila melanogaster. Funct Ecol 12:786-793.

Dix DJ and Luft JC (1999) HSP70 expression and function during oogenesis. Cell Stress Chaperones 4:162-170.

Feder ME and Hofmann GE (1998) Evolutionary and ecological physiology of heat shock proteins and heat shock response: A comprehensive bibliography. Annu Rev Physiol 61:243282.

Fristrom JW, Logan WR and Murphy NC (1973) The synthetic and minimal culture requirements for evagination of imaginal disc of Drosophila melanogaster in vitro. Dev Biol 33:441-456.

Gianguzza F, Ragusa MA, Roccheri AC, Di Liegro I and Rinaldi AM (2000) Isolation and characterization of a Paracentrotus lividus cDNA encoding a stress inducible chaperonin. Cell Stress Chaperones 5:87-89.

Gruntenko NE, Bownes M, Terashima J, Sukhanova MZ and Yu Raushenbach I (2003) Heat stress affects oogenesis differently in wild-type Drosophila virilis and a mutant with altered juvenile hormone and 20-hydroxyecdysone levels. Insect Mol Biol 12:393-404.

Hartl FU and Hayer-Hartl M (2002) Molecular chaperones in the cytosol: Nascent chain in folded proteins. Science 295:1852-1858.

Heikkila JJ, Browder LM, Genamu L, Nickels RW and Schultz GA (1986). Heat shock gene expression in animal embryonic systems. Can J Genet Cytol 28:1093-1105.

Heikkila JJ, Miller JGO, Schultz GA, Kloe M and Browder LW (1985) Heat shock gene expression during early development. In: Atkinson BG and Walden DB (eds) Changes in Eukaryotic Gene Expression in Response to Environmental Stress. Academic Press Inc, Orlando, pp 135-158.

Heikkila JJ, Ohan N, Tam Y and Ali A (1997) Heat shock protein gene expression during Xenopus development. Cell Mol. Life Sci 53:14-121.

Ireland RC and Berger EM (1982) Synthesis of low molecular weight polypeptides Stimulated by Ecdysterone in a Cultured Drosophila Cell Line. Proc Natl Sci 79:855-859.

King RC (ed) (1970) Ovarian development in Drosophila melanogaster. Academic Press, New York, 227 pp.

Kozhanova NI (2000) Hormonal regulation of gametogenesis in insect. Tsitologiia 42:115-127.
Krebs RA and Feder ME (1997) Tissue specific variation in Hsp70 expression and thermal damage in Drosophila melanogaster larvae. J Exp Biol 200:2007-2015.

Kregel KC (2002). Molecular biology of thermoregulation. Invited Review: Heat shock proteins: Modifying factors in physiological stress responses and acquired thermotolerance. J Appl Physiol 92:2177-2186.

Laemmli UK (1970). Cleavage of structural proteins during assembly of head of bacteriophage T4. Nature 227:682-685.

Lakhotia SC and Singh BN (1996) Synthesis of ubiquitously present new hsp60 family protein is enhanced by heat shock only in the Malpighian tubules of Drosophila. Experientia 52:751-756.

Lakhotia SC, Srivastava P and Prasanth KV (2002) Regulation of heat shock proteins Hsp70 and Hsp64 in heat shocked Malpighian tubules of Drosophila melanogaster larvae. Cell Stress Chaperones 7:347-356.

Michaud S, Marin R and Tanguay RM (1997) Regulation of heat shock gene induction and expression during Drosophila development. Cell Mol Life Sci. 53:104-113.

Morimoto RI (1998) Regulation of heat shock transcriptional response: Cross talk between a family of heat shock factors, molecular chaperones and negative regulators. Genes Dev 12:3788-3896.

Nollen EAA, Brunsting JF, Roelofsen H, Waber LA and Kampinga HH (1999) In vivo chaperone activity of heat shock protein 70 and thermotolerance. Mol Cell Biol 19:20692079.

Paranko J, Seitz J and Meinhardt A (1996) Developmental expression of heat shock protein 60 (HSP60) in rat testes and ovary. Differentiation 60:159-167.

Rauschenbach IY, Grutenko NE, Bownes M, Karpova EK, Chentsova NA, Sukhanova MZ and Adoneva NV (2003) Ecdysteroids and juvenile hormone control the early and late stages of oogenesis, respectively during stress in Drosophila. Dokl Biol Sci 389:127-9.

Sambrook J, Fritsch E and Maniatis T (1989) Molecular Cloning: A Laboratory Manual. Cold Spring Harbor Laboratory Press, New York, pp 18.2-18.75.

Sejerkilde M, Sorensen JG and Loeschcke V (2003) Effect of cold and heat hardening in thermal resistance and HSP70 expression in Drosophila melanogaster. J Insect Physiol 49:719726.

Sharma S, Reddy PVJ, Rohilla MS and Tiwari PK (2006) Expression of HSP60 homologue in sheep blowfly Lucilia cuprina during development and heat stress. J Thermal Biol 31:546-555.

Singh AK and Lakhotia SC (2000) Tissue specific variation in the induction of Hsp70 and Hsp64 by heat shock in insects. Cell Stress Chaperone 5:90-97.

Sirtokin K and Davidson N (1982) Developmentally regulated transcription from Drosophila melanogaster chromosomal site 67B. Dev Biol 89:196-205.

Sorensen JG, Kristensen NT and Loeschcke V (2003) The evolutionary and ecological role of heat shock proteins. Ecol Letters $6: 1-13$.

Soller M, Bownes M and Kubli E (1999) Control of oocyte maturation in sexually mature Drosophila females. Dev Biol 208:335-57. 
Soti C, Pal C, Papp B and Scermely P (2005) Molecular chaperones as regulatory elements of cellular network. Curr Opin Cell Biol 17:210-215.

Spradling AC (1993) Developmental genetics of oogenesis. In: Bate $\mathrm{M}$ and Arias AM (eds) The Development of Drosophila melanogaster. Cold Spring Harbor Laboratory Press, New York, pp 1-70.

Tiwari PK, Archana J and Mohan DRK (1997) Thermotolerance and heat shock response in Musca domestica. Curr Sci 72:501-506.

Tiwari PK, Mohan DRK and Archana J (1995) Developmental study of thermotolerance and the heat shock response in Lucilia cuprina (Weidemann). J Biosci 20:341-354.
Wigglesworth VB (1965) Circulatory system and associated tissues. In: The Principles of Insect Physiology. 6th ed. English Language Book Society \& Methuen \& Co Ltd., London, pp 442-451.

Zatsepina OG, Ulmasov KH, Beresten SF, Molodtsov VB, Rybtsov SA and Evgen 'ev, (2000) Thermotolerant desert lizards characteristically differ in terms of heat shock system regulation. J Exp Biol 203:1017-1025.

Zimmerman JL, Petri W and Meselson M (1983) Accumulation of specific subset of D. melanogaster heat shock mRNAs in normal development without heat shock. Cell 32:11611170 .

Associate Editor: Carlos F.M. Menk 